\title{
Level Assessment of Ecological Environment of China and Sustainable Development Strategies
}

\section{Yong Li}

School of Marxism, Huanghuai University, Zhumadian 463000, China

†Corresponding author: Yong Li: 178719267@qq.com

Nat. Env. \& Poll. Tech. Website: www.neptjournal.com

Received: 05-03-2021

Revised: 02-04-2021

Accepted: 15-04-2021

Key Words:

Ecological Environment

Level Assessment

Sustainable Development strategy

\begin{abstract}
China's ecological environmental level is not high because of the intensifying resource constraint, heavy environmental pollution, and ecosystem degradation. The highly industrialized process leads to resource exhaustion, energy shortage, environmental deterioration, and ecological imbalance, which threaten sustainable economic growth and social progress. Effective living environmental level assessment in different provinces in China is an important premise to insist on the new development mode of high resource utilization, good environmental protection effect, and evident ecological efficiency in the new stage. In this study, studies on ecological environment level assessment and sustainable development strategies of the ecological environment were summarized. An ecological environment level assessment index system was constructed from the perspectives of water environment, living environment, forest environment, agricultural environment, and sudden environmental event. The ecological environmental level measurements of 31 provinces, municipalities, and autonomous regions in China in 2019 were measured by the entropy weight-technique for order preference by similarity to an ideal solution (TOPSIS) model. Results demonstrate that total water resources, forestry investment, and completed investment in industrial pollution control are the three most important indexes to measure the ecological level of a province, which account for $50 \%$ of weights. The relative closeness (C) of TOPSIS estimation results range in the interval of $0.215-0.510$. The ecological environmental level of 31 provinces, municipalities and autonomous regions in China in 2019 could be generally divided into three types. To realize China's ecological environment and economic social coordinated development, some sustainable development strategies, including 1) optimizing energy structure and accelerating economic development; 2) strengthening environmental control and relieving industrial waste emissions; 3 ) strengthening ecological construction planning and increasing law enforcement in ecological environmental pollution; 4) increasing bearing capacity of ecological environment and protecting ecological environment sustainable development, were proposed. Research conclusions have an important role in exploring the current provincial ecological environmental levels, promoting coordinated development of the economy-resource-environment system, and enriching policies concerning China's ecological environment sustainable development.
\end{abstract}

\section{INTRODUCTION}

The ecological environment is the basis of human survival. However, resource exhaustion and environmental pollution caused by the increase in the artificial reconstruction of nature are serious threats to the sustainable social development of human. Therefore, strengthening ecological civilization construction and establishing a resource-saving and environmental-friendly society that takes the bearing capacity of resource environment as the basis, natural laws as the criteria, and sustainable development as the objective are great events that are related with the overall human and social development, which have become two national strategies. With the progress in industrialization and urbanization, demands of the social-economic system for natural resources and pollutant emissions increase significantly. Many factors have influenced the health of the ecological environment. Sustainable development theory is a key to solve resource environmental bottleneck in the process of regional development, and it has become a research hotspot on geoscience and environmental science. The implementation of the sustainable development strategy of ecological environmental governance is an important aspect and an effective tool in realizing the harmonious development of the ecological environment and economic society. Nowadays, this stage is an important phase that Chinese cities are facing with transformation and upgrading. In the past decades, urban construction development in China is an old strategy at the cost of the environment, and it brought many ecological environmental pollution phenomena. For example, the healthy lifestyle of people has been challenged by urban expansion, extensive division 
of urban functional regions, traffic jam, and environmental deterioration. Facing the serious situation of decreasing the bearing capacity of the resource environment and deteriorating urban ecosystem in China, the application of the philosophy of sustainable development into ecological environmental protection is suggested.

Negative external environmental issues, such as atmospheric pollution, global warming, soil-water loss and water quality deterioration, become increasingly prominent in China because of industrialization and urbanization and have brought economic prosperity and social progress. Severe environmental pollution and ecological failure not only threaten the physical health and property safety of people but also restrict the improvement of human development and life level and influence the benefits of several generations. Ecological environmental safety is faced with unprecedented challenges. Although China has achieved outstanding successes in economic construction, environmental pollution problems and ecological environmental damages are intensifying continuously. This series of problems attracts growing attention as the consciousness of citizens toward environmental protection rises and living quality and demands for a high-quality ecological environment are increased. Proposing sustainable development strategies by accurate and objective measurement of ecological environmental levels in provinces in China has important theoretical significance and practical values.

\section{EARLIER STUDIES}

Ecological environmental level assessment and strategies on sustainable development study have been the research hotspots worldwide. As an effective measurement and management mean of economy-resource environmental coordinated sustainable development, the accurate measurement of ecological environmental level has been widely applied in many countries. With respect to ecological environmental level assessment, De Lange et al. summarized the applications of ecological vulnerability analysis in rick assessment, introduced new progress in ecological vulnerability analytical methodology, and proposed a new ecological vulnerability analysis frame that could be used as a part of ecological risk assessment and used in risk management (De Lange et al. 2010). Liu et al. believed that the balance between China's economic development and ecological protection became a key problem. Given that ecological impact assessment is a component of environmental impact assessment, he summarized the general trend of ecological impact assessment development to show future development tracks (Liu et al. 2015). Munns et al. carried out an ecological risk assessment on ecosystem services in America and found that ecosystem service was used as an assessment end to increase the values of risk assessment to environmental decision-making. He suggested the combination of ecological risk and human welfare and provided a better way to express these risks (Munns et al. 2016). Chu et al. evaluated the current water quality in the Qili Sea wetland in China and recognized the pollution source. Supported by data in 2010-2013, he established a water quality evaluation index system by single-factor assessment and comprehensive evaluation method. According to the evaluation results, the water pollution in the Qili Sea wetland was serious (Chu et al. 2017). Meng et al. believed that the construction of the Olympic Winter Games had some ecological impacts in mountain regions with the sensitive and vulnerable ecosystem and evaluated multi-scale suitability of ecological suitability development in Olympic Winter Games areas based on the ecological suitability evaluation method of GIS spatial analysis (Meng et al. 2018). He et al. constructed a comprehensive ecological vulnerability index that could describe vulnerability conditions in hotspot ecological zones in China and proved the poor ecological vulnerability in China. According to spatial comparison, the spatial difference in the ecological vulnerability in China is observed. Specifically, the ecological vulnerability in provinces in Northwest China was higher than those in Northeast China and Southern China (He et al. 2018). Chen et al. assessed the influences of the improved group AHP-FCE model on the ecological environment in highway construction, which had outstanding applicability and promotion values in ecological environmental assessment (Chen et al. 2020). They believed that the wetland ecosystem had comprehensive ecological functions, and it was sensitive to climate changes. They studied changes in productivity and diversity of plants in the ecosystem in Sanjiang Plain in China. The results showed that wetland protection and management should focus on hydrological configuration and potential ecological risk in the national wetland nature reserve (Chen et al. 2020). With respect to ecological environmental sustainable development strategies, Fu et al. believed that how the local government cope with and promote sustainable development under the environmental decentralization system were important problems. Research results demonstrated that public consciousness, financial imbalance, and market-oriented reform could increase law enforcement efforts of local governments in environmental protection and promote ecological environment sustainable development (Fu et al. 2019). Bu et al. (2019) proposed a game model of social welfare maximization and analyzed the policy of how the government adjusts the total sewage emission control timely according to sewage stock under relevant policies. He suggested that the government should pay more attention to provide capital and technical support 
to enterprises with fund shortage and poor technological level. Chandel et al. (2020) believed that dependence on fossil fuel was increasing stupendously, thereby resulting in the resource exhaustion state. A new sustainable biological energy source method was needed. Thus, emission reduction and even the implementation of a zero-emission policy are important pathways to realize the sustainable development of biological energy source. Khim et al. investigated scientific evidence on the association between the sustainable development objectives of Belgium and the United Nations (UN), as well as the correlation and consistency of stakeholders in the relationship between Belgium and sustainable development. He believed that determining a realizable objective and indexes of sustainable development goal played an important role in economic prosperity and social development (Khim et al. 2020). Abdul-Rahaman et al. studied the effects of foreign direct investment (FDI) on China's sustainable development by using a regression model. Results demonstrated that the implementation of stricter environmental policies and strategies can decrease breaches of contract of foreign investors (Abdul-Rahaman et al. 2020). Xuan chang et al. believed that ecological restoration, economic development, and social progress were related to the realization of the national sustainable development objective directly. A sustainable LP sustainable development strategy was proposed based on the 3Cs (classification, coordination and cooperation) system method (Xuanchang et al. 2021). Ahl et al. (2021) believed that biological technology played a key role in changing the existing land use system, and it could increase the productivity of farm or planting gardens, supplement deterioration land, and improve the bearing capacity of the ecological environment. Existing associated studies on the ecological environmental level focus on the ecological design of products, system development, and guidance of enterprise sustainable development. In China, few studies on the ecological effect of enterprises and products are mostly qualitative analysis of ecological environmental level on the regional scale and industrial fields. Chinese enterprises pay insufficient attention to ecological environmental protection, and inadequate statistical data on the ecological environment of Chinese enterprises and products are available. Studies on the sustainable protection mechanism of the regional ecological environment are not thorough yet. Hence, an ecological environmental level assessment system was constructed based on the data of 31 provinces, municipalities, and autonomous regions of China in 2019. The ecological environmental level in different provinces was measured by the entropy weight-TOPSIS model. Finally, sustainable development strategies that can improve different regional ecological environmental levels were proposed.

\section{MODEL INTRODUCTION AND CONSTRUCTION OF INDEXES}

\section{Brief Introduction to Entropy Weight-TOPSIS Model}

The concept of entropy originated from thermodynamics, and it is a parameter that characterizes the substance state. Entropy is a measurement of the degree of system disordered. An index with the smaller information entropy can provide a bigger information size, plays more role in the comprehensive evaluation, possesses higher weight, and imposes greater impacts on evaluation structures. Entropy has been widely applied in studies on system engineering, economical, and social studies, which have achieved many successes. The calculation of entropy can be performed as follows.

First, the evaluation factor matrix is expressed in Eq. (1) as:

$$
A=\left[\begin{array}{ccc}
a_{11} & \cdots & a_{1 n} \\
\vdots & & \vdots \\
a_{m 1} & \cdots & a_{m n}
\end{array}\right]
$$

where $m$ is the evaluated object and referred to 31 provinces in this study. $n$ refers to the number of factors that influence the comprehensive index of ecological environmental level. Through the standardization of factor matrix $A$, the range transformation formula was applied for dimensionless data processing. The positive index was processed by Eq. (2).

$$
r_{i j}=\frac{a_{i j}-\min \left(a_{i j}\right)}{\max \left(a_{i j}\right)-\min \left(a_{i j}\right)}
$$

The negative index was processed by Eq. (3).

$$
r_{i j}=\frac{\max \left(a_{i j}\right)-a_{i j}}{\max \left(a_{i j}\right)-\min \left(a_{i j}\right)}
$$

In Eqs. (2) and (3), $a_{i j}$ is an element in the evaluation factor matrix.

Entropy is used to characterize information size. The factor that carries the bigger information size has larger entropy. The system entropy can be expressed as:

$$
H_{i}=\left(P_{1}, P_{2}, P_{3}, \ldots, P_{4}\right)=-K \sum_{i=1}^{m} P_{i} \operatorname{Ln}\left(P_{i}\right),(i=1,2, \ldots, m)
$$

Where, $k=1 / \ln (m)$ and $m$ refers to the state that the system might be in. $P_{i}$ is the probability of occurrence of a state of the system. $0<P_{i}<1, \Sigma P_{i}=1$. When $P_{i}=0$, then:

$$
-K \sum_{i=1}^{m} P_{i} \operatorname{Ln}\left(P_{i}\right)=0
$$

By combining the standardized characteristic matrix gained from Eq. (5), the entropy of factor $i$ is:

$$
H_{i}=-K \sum_{i=1}^{m} f_{i j} \operatorname{Ln}\left(f_{i j}\right), f_{i j}=\frac{a_{i j}}{\sum_{i=1}^{m} a_{i j}}
$$


Finally, the entropy weight of factor $i$ is defined as:

$$
W_{j}=\frac{1-H_{i}}{\sum_{i=1}^{n}\left(1-H_{i}\right)}
$$

Subsequently, a weighted normalization matrix (Eq. (8)) was formulated.

$$
R=\left(V_{i j}\right)_{m \times n}=\left[\begin{array}{rrrrr}
W_{1} r_{11} & W r_{2} & 2 & \ldots & W_{n} r_{n} \\
W_{1} r_{2} & W r_{2} & 22 . . & W_{n} r_{n} \\
& & \ldots & \\
W_{1} r_{m 1} & W r_{2 n} & 1 & \ldots & W_{n} r_{m n}
\end{array}\right]
$$

Next, the positive ideal solution $\left(V^{+}\right)$and negative ideal solution $(V)$ of the evaluation scheme were determined and shown in Eq. (9).

$$
V^{+}=\max \left(V_{i 1}, V_{i 2}, \ldots, V_{i n}\right), V^{-}=\min \left(V_{i 1}, V_{i 2}, \ldots, V_{i n}\right)
$$

The Euclidean distances from various indexes to the optimal and the worst vectors were calculated:

$$
D_{i}^{+}=\sqrt{\sum_{j=1}^{m}\left(V_{i j}^{+}-V_{i j}\right)^{2}}, D_{i}^{-}=\sqrt{\sum_{j=1}^{m}\left(V_{i j}^{-}-V_{i j}\right)^{2}},
$$

Finally, the comprehensive evaluation index of ecological environmental level of different provinces was calculated:

$$
C_{i}=\frac{D_{i}^{-}}{D_{i}^{+}+D_{i}^{-}}, 0 \leq C_{i} \leq 1(i=1,2, \ldots, m)
$$

\section{Construction of Indexes}

Currently, no uniform index system is available for ecological environmental level assessment in the academic circle. Based on existing literature, the ecological environmental level is defined as when people attempt to reduce waste emissions during daily production and life activities, prevent environmental pollution effectively, and protect and continuously optimize natural ecological environmental society, that is, the human-environmental harmonious society; people's efforts in protecting, improving, and optimizing the environment; and current support degree of the environment to the sustainable development of society and economy. Based on the review of abundant comprehensive evaluation index system of ecological environmental level, an evaluation index system of the provincial ecological environmental level was constructed by observing five principles of scientificity, objective, comparability, hierarchy, and operability and referred to previous selection of relevant indexes. The system is shown in Table 1.

In this study, the ecological environmental index data in 31 provinces, municipalities, and autonomous regions in China in 2019 were collected from the China National Statistics Library (https://data.stats.gov.cn/).

\section{EMPIRICAL STUDY}

The numerical values of specific indexes were determined according to the collected data. First, ecological environmental index data in 31 provinces, municipalities, and autonomous regions in China in 2019 were normalized. The entropy weights of indexes were calculated from Eqs. (1)-(7). The

\begin{tabular}{|c|c|c|c|c|}
\hline Level-1 indexes & Level-2 indexes & Index No. & Unit & Type of indexes \\
\hline \multirow[t]{3}{*}{ Water environment } & Total water supply & A1 & 100 million cubic meters & - \\
\hline & Total water resources & A2 & 100 million cubic meters & + \\
\hline & Total ecological water consumption & A3 & 100 million cubic meters & - \\
\hline \multirow[t]{3}{*}{ Living environment } & Amount of household garbage clean-up & $\mathrm{B} 1$ & 10,000 tons & - \\
\hline & Harmless disposal of household wastes & B2 & $\%$ & + \\
\hline & Number of harmless treatment plants & B3 & Plants & + \\
\hline \multirow[t]{5}{*}{ Forest environment } & Total afforestation area & $\mathrm{C} 1$ & 1000 ha. & + \\
\hline & forestry investment & $\mathrm{C} 2$ & 10,000 yuan & + \\
\hline & Number of forest fire disasters & $\mathrm{C} 3$ & Times & - \\
\hline & Forest area of diseases and pests & $\mathrm{C} 4$ & 10,000 ha. & - \\
\hline & Forest coverage & $\mathrm{C} 5$ & $\%$ & + \\
\hline \multirow[t]{3}{*}{ Agricultural environment } & Crop failure area & D1 & 1000 ha. & - \\
\hline & Affected population of natural disasters & D2 & Per 10,000 users & - \\
\hline & Direct economic loss of natural disasters & D3 & 100 million yuan & - \\
\hline \multirow[t]{2}{*}{ Sudden events } & Number of sudden environmental events & E1 & Times & - \\
\hline & completed investment to industrial pollution control & E2 & 10,000 yuan & + \\
\hline
\end{tabular}
weights of relevant indexes were determined according to the general influences of their relative variations on the system. Therefore, indexes with greater relative variations possess

Table 1: Ecological environmental evaluation index system.

(In Table $1,+$ indicates that the index is a positive index, and a higher numerical value indicates better ecological environment-indicates that this index is a negative index, and a higher numerical value indicates a poorer ecological environment.) 


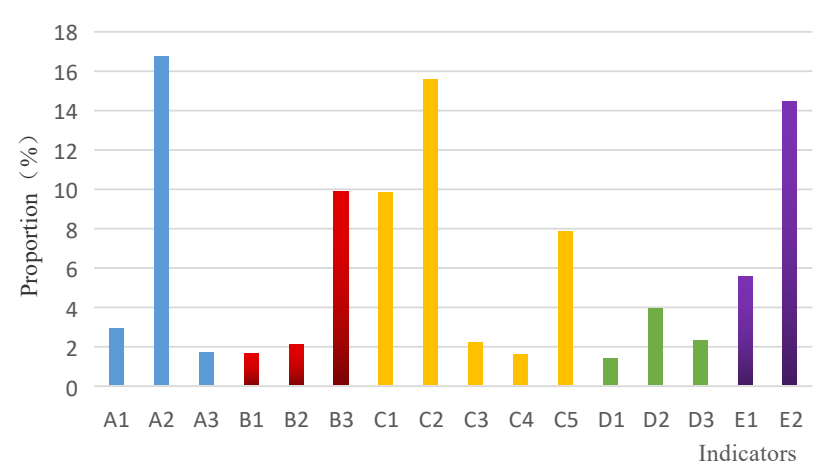

Fig. 1: Weights of the evaluation indexes.

higher weights. In other words, the index with smaller information entropy has a greater utility value.

Fig.1 shows that total water resources (A2), forestry investment $(\mathrm{C} 2)$, and completed investment in industrial pollution control (E2) are the three most important indexes in measuring the ecological level of a province. The proportion of these indexes reached as high as $50 \%$. Considering that China is a country with a relative per capita water resource shortage, especially in Northwest China, water shortage becomes the most important index in measuring a regional ecological environmental level. Forestry investment increases annually and became the second most important index of ecological environmental level. Increasing completed investment in industrial pollution control can control industrial environmental pollution in different provinces and improve "three industrial waste" pollution brought by the high-speed industrial development in China.

TOPSIS analysis was carried out by the data produced by weighting after entropy weight method to determine the evaluation indexes and assure that all evaluation indexes have a positive trend (the index with the higher value is suitable). According to Eqs. (7)-(10), the results in Table 2 were calculated. In Table 2, D+ and D- referred to the distances from the evaluation objects to the positive and negative ideal solutions. $\mathrm{C}$ refers to the closeness between the evaluation objects and the optimal scheme. The higher value of $\mathrm{C}$ indicates that the scheme is closer to the optimal scheme.

Table 2 presents that: (1) Shandong Province, Guangdong Province, Guangxi Zhuang Autonomous Region, and Tibet

Table 2: TOPSIS Estimation results.

\begin{tabular}{|c|c|c|c|c|}
\hline $\begin{array}{l}\text { Provinces } \\
\text { Indexes }\end{array}$ & $\begin{array}{l}\text { Positive ideal solution distance } \\
\text { D }\end{array}$ & $\begin{array}{l}\text { Negative ideal solution distance } \\
\text { D- }\end{array}$ & $\begin{array}{l}\text { Relative closeness } \\
\text { C }\end{array}$ & Rank \\
\hline Beijing & 0.279 & 0.1 & 0.263 & 24 \\
\hline Tianjin & 0.302 & 0.089 & 0.228 & 30 \\
\hline Hebei Province & 0.241 & 0.13 & 0.351 & 11 \\
\hline Shanxi Province & 0.259 & 0.104 & 0.287 & 18 \\
\hline Inner Mongolia Autonomous Region & 0.248 & 0.136 & 0.354 & 9 \\
\hline Liaoning Province & 0.276 & 0.093 & 0.251 & 29 \\
\hline Jilin Province & 0.275 & 0.100 & 0.266 & 23 \\
\hline Heilongjiang Province & 0.252 & 0.114 & 0.311 & 15 \\
\hline Shanghai & 0.290 & 0.100 & 0.256 & 26 \\
\hline Jiangsu Province & 0.254 & 0.131 & 0.340 & 13 \\
\hline Zhejiang Province & 0.233 & 0.134 & 0.365 & 7 \\
\hline Anhui Province & 0.257 & 0.096 & 0.272 & 22 \\
\hline Fujian Province & 0.241 & 0.127 & 0.346 & 12 \\
\hline Shanxi Province & 0.231 & 0.132 & 0.363 & 8 \\
\hline Shandong Province & 0.222 & 0.187 & 0.457 & 2 \\
\hline Henan Province & 0.260 & 0.100 & 0.279 & 19 \\
\hline Hubei Province & 0.247 & 0.109 & 0.307 & 16 \\
\hline Hunan Province & 0.218 & 0.144 & 0.398 & 6 \\
\hline Guangdong Province & 0.216 & 0.162 & 0.428 & 3 \\
\hline Guangxi Zhuang Autonomous Region & 0.197 & 0.204 & 0.510 & 1 \\
\hline Hainan Province & 0.298 & 0.111 & 0.272 & 21 \\
\hline Chongqing & 0.274 & 0.103 & 0.274 & 20 \\
\hline Sichuan Province & 0.206 & 0.147 & 0.417 & 5 \\
\hline Guizhou Province & 0.239 & 0.117 & 0.329 & 14 \\
\hline Yunnan Province & 0.236 & 0.129 & 0.353 & 10 \\
\hline Tibet Autonomous Region & 0.258 & 0.19 & 0.425 & 4 \\
\hline Shaanxi Province & 0.253 & 0.104 & 0.292 & 17 \\
\hline Gansu Province & 0.276 & 0.098 & 0.262 & 25 \\
\hline Qinghai Province & 0.283 & 0.095 & 0.252 & 28 \\
\hline Ningxia Hui Autonomous Region & 0.303 & 0.083 & 0.215 & 31 \\
\hline Xinjiang Uygur Autonomous Region & 0.267 & 0.091 & 0.254 & 27 \\
\hline
\end{tabular}


Autonomous Region show the best ecological environment. $\mathrm{C}$ of these four provinces was higher than 0.425 , which was far higher than those of the other provinces. Guangxi Zhuang Autonomous Region and Tibet Autonomous Region are mainly located in provinces with the backward economy in the national border in Western China. These regions have good ecological environmental quality and provide important environmental inclusiveness. Guangdong Province and Shandong Province play an important role in investment in environmental protection because they have the maximum total economic development. Abundant capitals to environmental pollution control can assure a remarkable ecological environmental level. In these provinces, citizens became aware of ecological environmental protection earlier, and relevant policies and laws are perfect. Local governments support the construction of ecological cities and the development of ecological industry, respect objective natural laws, and maintain accurate ecological philosophy. They realize collaborative progress in economic development and environmental protection. To realize sustainable development truly, great efforts are made to promote the development and use of clean energy, and production and lifestyle of energy saving and emission reduction are advocated. Citizens generally have strong consciousness toward environmental protection, the implementation of the philosophy of environmental protection in daily life, and the formation of advanced ecological civilization. As such, the conventional conclusion proves indirectly that the ecological environment in the early stage of industrialization was good because of the light industrial pollution and high economic gross in the late stage of industrialization, thereby resulting in the high efficiency of environmental pollution.

(2) Hebei Province, Inner Mongolia Autonomous Region, Zhejiang Province, Hunan Province, and Yunnan Province show the second-best ecological environment. The ecological environment in these provinces belong to the average level in China, and the environment is lightly friendly. These provinces belong to the mild environmental-friendly society, and most of them are in central China, which still has certain differences from developed regions. These provinces belong to resource relative consumption type because local industrial structures and scale effect are not evident enough. Generally, the environmental-friendly comprehensive scores of these provinces are basically in the middle level. Economic development mode in these provinces proposes an urgent demand for the transformation to a modernized intensive economy and high-level industrial structure. The industrial development level of these provinces is relatively high because of advanced technology and high production efficiency, which decreases energy wastes and waste emission pollutions. Influenced by the "deindustrialization" tide, these provinces not only reduce the proportion of heavy industries positively and make great efforts to develop ecological-friendly industries and new energy sources but also strengthen citizens' consciousness of ecological protection and promote the exploration in green sustainable economic development.

(3) The remaining regions, including Tianjin, Beijing, and Shanxi, have a backward ecological environment. Most of these regions have witnessed haze and serious environmental pollution in recent years. The mean environmental-friendly comprehensive score of these provinces is far lower than those of other provinces. These regions have poor ecological environmental quality and low environmental bearing capacity, and shall further strengthen environmental control. People in these regions have poor consciousness toward ecological protection, and they ignore environmental damages in economic development. Economic development emphasizes resource mining and primary processing, and it is characterized by high energy consumption, high environmental pollution, low production efficiency, and low economic benefits. These regions need industrial upgrading urgently and have to pay attention to the relation between ecological environmental protection and economic development. The provincial economic social development level in these regions is generally low, and it cannot consider ecological environmental protection simultaneously. The quality of local citizens has to be improved. Moreover, ecological environmental damages are relatively serious, thereby taking a long time to restore. Among these regions, some provinces mainly depend on husbandry development and they rely highly on the natural environment and climate. Furthermore, the ecological environment might be overused. The use of primary product processing as the major industrial-economic mode not only has low economic benefits but may also have low resource utilization because of the background production technology and immature technological level. Consequently, it might cause energy overuse and waste emission environmental pollution. Finally, to make it easier to understand, the $\mathrm{C}$ of 31 Provinces, Municipality and Autonomous Regions in China is shown in Fig. 2 in 2019.

\section{SUSTAINABLE DEVELOPMENT STRATEGIES OF IMPROVING ECOLOGICAL ENVIRONMENTAL LEVEL}

\section{Optimizing Energy Structure and Accelerating Economic Development}

China must strengthen the consciousness of energy saving in production, transportation, and consumption; increase efforts in cyclic economic development; improve energy use structure, increase industrial structure; reduce energy consumption 


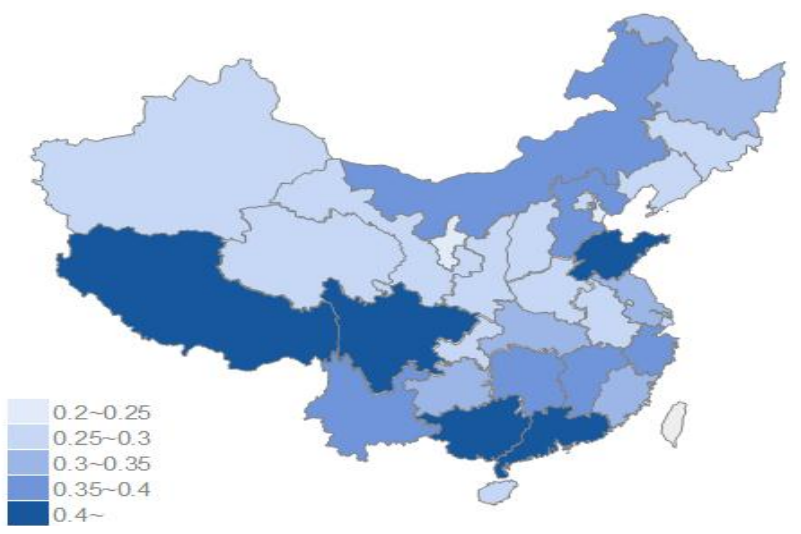

Fig. 2: $C$ of 31 Provinces, Municipality and Autonomous Regions in China in 2019.

per GDP through a series of measures; and increase economic development quality. Additionally, China has to: 1) lower energy consumption at the terminal consuming enterprises by using advanced technologies and techniques and developing a cyclic economy. 2) Improve energy structure in industrial and agricultural production around the country and accelerate the development of clean energies, including solar energy, wind energy, and biological energy. 3) Establish a reasonable energy price formation mechanism. The value of energy shall be reflected through the market, and energy price shall be reflected by market supply-demand relations to encourage users to save energy and producers to increase investment to find substitutive energy sources. 4) Accelerate industrial structural updating, pay attention to the adjustment of industrial structure, increase support to new high-tech industries, such as environmental protection and new energy industries, and protect economic sustainable development. 5) Strengthen regional coordinated development, integrate regional resource advantages from the global perspective, form complementation of regional industrial advantages, realize regional resource sharing, environmental coexistence and coordinated development, increase overall economic competitiveness and benign interaction of regions, and drive the development of all economic circles in China.

\section{Strengthening Environmental Control and Relieving Industrial Waste Emissions}

The industrial layout shall be designed reasonably. Existing industrial layout and planning industrial layout shall have detailed arrangement and deployment. The planning industrial layout shall not be in urban areas. In particular, heavily polluted industrial enterprises are at the downwind places of the city that are far away from regions with high population density. The following approaches are suggested: 1) strengthen pollution source control and control the pollutant emission at the lowest extent. 2) Strengthen protection of drinking water sources and test water quality in source regions to discover illegal architectural structures and plants which might cause the water environment. These pollutions have to be solved properly, and the safety of drinking water must be protected. 3 ) Increase monitoring over rivers and efforts in pollution control and monitor and manage the corresponding pollutant discharging unit according to the requirement of water quality function. 4) Make plans on solid waste processing, the perfect system for solid waste collection in all cities, and prevent secondary pollution during the garbage disposal process in refuse landfills and garbage incinerator. 5) Classify solid wastes according to certain standards and process independently, and recycle according to unique properties.

\section{Strengthening Ecological Construction Planning and Increasing Law Enforcement in Ecological Environmental Pollution}

Experts in different fields must be organized to make a systematic and scientific ecological environmental construction plan. During the compilation of the system, various social-economic activities in cities have to be planned scientifically by combining the urban ecological status, urban economic social development strategies, and ecological environmental construction goal, thereby enabling to increase resource transformation efficiency of cities, energy-saving efficiency of facilitates, harmless processing rate of wastes, and self-cleaning capacity of urban ecological environment. Urban management shall be strengthened so that each detail in ecological urban construction is subjected to scientific urban management activities. Urban management requires a complete management system to manage economic activities, social construction, and natural environmental construction. Meanwhile, management departments at all levels shall strengthen correlations. It has to accelerate the establishment of laws and regulation system, which adapt to ecological urban development, to enlist ecological urban construction into the legalization orbit. This method is an effective way to protect ecological urban construction. In the process of ecological urban construction, encountering various behaviours that disagree with the ecological development of cities is inevitable. Hence, some laws and administrative means have to be adopted to assure smooth implementation of ecological urban construction. Ecological legislation can provide relevant legal guarantees. Protecting ecological urban construction by-laws is conducive to guide it to the road of legalization, planning, and systematism. 


\section{Increasing Bearing Capacity of Ecological Environment and Protecting Ecological Environment Sustainable Development}

Ecological civilization construction is based on the bearing capacity of the ecological environment. It has to accelerate the construction of ecological civilization pilot demonstrations and national ecological civilization test site. Under the hard constraint of bearing capacity of ecological environment, the following recommendations are presented: 1) adopt economic-environmental coordinated development and continue to promote ecological civilization construction in provinces in China. 2) Increase financial investment to environmental protection, innovate PPP mode of ecological construction, and expand investment and financial channels for environmental protection. 3) Increase investment in the construction of urban environmental infrastructure, adopt the new urbanization road, and construct ecological-oriented cities. 4) Implement natural resource property right system natural resource use control system, increase the area of natural reserves and inventory of per capita land and forest resources, determine a protection red line, increase the ecological space, and improve bearing capacity of ecological environment continuously. 5) Adapt to new normal status positively, implement structural reform on the supply side, insist on the development philosophy of "innovation, coordination, green, open, and sharing," promote development by new driving forces, transform economic motivations, increase total factor productivity, lower energy consumption and increase resource utilization, and relieve pressure over the ecological environment.

\section{CONCLUSIONS}

The rapid progress in industrialization and urbanization have brought a series of problems, including resource exhaustion, energy shortage, environmental deterioration, and ecological imbalance. These problems are against economic sustainable growth and social progress, thereby making ecological crisis appear gradually. Economic-resource environment coordinated sustainable development becomes a topic that is widely concerned in the world. Accordingly, the philosophy of sustainable development is proposed. China's economic growth is achieved at the cost of excessive resource consumption and environmental pollutions. Rapid industrialization further increases the pressure on the resource environment. In this study, an ecological environmental level assessment index system is constructed, and the ecological environmental level in 31 provinces, municipalities, and autonomous regions in China in 2019 is measured by the entropy weight-TOPSIS model. Results demonstrate that total water resources, forestry investment, and completed investment in industrial pollution control become the three most important indexes to measure the ecological level of a province. The relative closeness $(\mathrm{C})$ ranges in the interval of 0.215-0.510. The ecological environmental level of 31 provinces, municipalities and autonomous regions in China in 2019 could be divided into three types. To realize China's ecological environment and economic social coordinated development, some sustainable development strategies, including optimizing energy structure and accelerating economic development, strengthening environmental control and relieving industrial waste emissions, strengthening ecological construction planning and increasing law enforcement in ecological environmental pollution, increasing the bearing capacity of ecological environment, and protecting ecological environment sustainable development, were proposed. In-depth studies from perspectives of regional differences in ecological environmental level, perfect ecological efficiency evaluation index system, and multi-dimensional estimation of factors that influence regional ecological environmental level must be conducted in the future.

\section{REFERENCES}

Abdul-Rahaman, A. R., Ayamba, E. C., Haibo, C., Osei-Agyemang, A. and Serwaa, O. E. 2020. The impact of foreign direct investment on sustainable development in China. Environmental science and pollution research international, 27(20): 25625-25637.

Ahl, A., Goh, C. S. and Woo, W. T. 2021. Sustainable Transformation of Land-Based Economic Development in the Era of Digital Revolution. Trends in Biotechnology, 39(1): 1-4.

Bu, Y., Cheng, J., Guo, M. and Jiang, Z. 2019. Supporting Sustainable Development of Water Resources: A Social Welfare Maximization Game Model. International journal of environmental research and public health, 16(16): 2896.

Chen, B., Chen, W., Fu, J., Liu, J., Wang, X. and Zhang, M. 2020. Ecological risk assessment of wetland vegetation under projected climate scenarios in the Sanjiang Plain, China. Journal of environmental management, 273,111108 .

Chandel, A. K., Dhanya, B. S., Mishra, A. and Verma, M. L. 2020. Development of sustainable approaches for converting the organic waste to bioenergy. The Science of the total environment, 723: 138109.

Chu, C., Ju, M., Liu, L., Ruan, X., Xu, S. and Zhang, Y. 2017. Water Environment Assessment as an Ecological Red Line Management Tool for Marine Wetland Protection. International journal of environmental research and public health, 14(8): 870.

Chen, Y., Yang, C., Yang, S., Wang, Z. and Zhang, D. 2020. Assessment of ecological environment impact in highway construction activities with improved group AHP-FCE approach in China. Environmental monitoring and assessment, 192(7): 451.

De Lange, H. J., Faber, J. H., Sala, S. and Vighi, M. 2010. Ecological vulnerability in risk assessment--a review and perspectives. The Science of the total environment, 408(18): 3871-3879.

Fu, S., Tang, P. and Zeng, H. 2019. Local government responses to catalyse sustainable development: Learning from low-carbon pilot programme in China. The Science of the total environment, 689: 1054-1065.

He, L., Shen, J. and Zhang, Y. 2018. Ecological vulnerability assessment for ecological conservation and environmental management. Journal of environmental management, 206: 1115-1125. 
Khim, J. S., Lee, K. H. and Noh, J. 2020. The Blue Economy and the United Nations' sustainable development goals: Challenges and opportunities. Environment International, 137: 105528.

Liao, C., Li, D., Liu, X., Li, Y., Li, Z., Tang, Z., Wang, Q. and Zhu, A. 2015. The development of ecological impact assessment in China. Environment International, 85: 46-53.

Munns, W.R., Rea, A.W., Suter, G.W., Martin, L., Blake-Hedges, L., Crk, T., Davis, C., Ferreira, G., Jordan, S., Mahoney, M. and Barron, M.G.

2016. Ecosystem services as assessment endpoints for ecological risk assessment. Integrated environmental assessment and management, 12(3): 522-528.

Meng, J., Song, S., Wang, T., Zhang, H., Zhang, S. and Zhou, Y. 2018. Balancing conservation and development in Winter Olympic construction: evidence from a multi-scale ecological suitability assessment. Scientific reports, 8(1): 14083.

Xuanchang, Z., Yansui, L., Yurui, L., Zhengjia, L., Zhi, C. and Zhi, L. 2021. Towards the progress of ecological restoration and economic development in China's Loess Plateau and strategy for more sustainable development. The Science of the total environment, 756: 143676. 